\title{
Article \\ Questioning the Policy Framing of Roma in Ghent, Belgium: Some Implications of Taking an Insider Perspective Seriously
}

\author{
Elias Hemelsoet* and Pauwel Van Pelt + \\ Social Welfare Studies Department, Ghent University, 9000 Ghent, Belgium; E-Mail: elias.hemelsoet@gmail.com \\ $\dagger$ Deceased \\ * Corresponding author
}

Submitted: 31 January 2015 | In Revised Form: 1 April 2015 | Accepted: 8 April 2015 |

Published: 29 September 2015

\begin{abstract}
The recent flow of Roma immigrants to Western Europe has caused a lot of societal and political discussion. Initiatives and policy measures are introduced at the European and national or local level in order to deal with this situation. This article explores to what extent experiences and self-perceptions of Roma immigrants in Western Europe correspond with the constructed discourse in terms of "Roma inclusion". In policy practices, there seems to be a tension between a willingness to strengthen the particular identity of Roma on the one hand ("targeting"), and a desire to fit those people into mainstream society on the other hand ("mainstreaming"). Based on a case study in the city of Ghent (Belgium) with a small sample of in-depth interviews, the authors explore what an insider perspective may add to the construction of policy. Conclusions relate to the experienced gap with mainstream society, the identification with and definition of the "Roma" concept as well as intergenerational differences. Finally, the argument is taken a step further, and it is wondered how an insider perspective may also question policy. By relating policy conceptualisations of Roma to (self) identification processes, suggestions are made to redefine the meaning of inclusion.
\end{abstract}

\section{Keywords}

Ghent; inclusion; insider perspective; mainstreaming; Roma; self-identification; social policy; targeting

\section{Issue}

This article is part of the special issue "Talking about Roma: Implications for Social Inclusion", edited by Dr. Eben Friedman (Independent Consultant and Senior Non-resident Research Associate, European Centre for Minority Issues, Germany).

(C) 2015 by the authors; licensee Cogitatio (Lisbon, Portugal). This article is licensed under a Creative Commons Attribution 4.0 International License (CC BY).

\section{Introduction}

In 2004 and 2007 the European Union was extended to a number of Central and Eastern European countries, i.e. Hungary, Estonia, Latvia, Lithuania, Slovenia, the Czech Republic and the Slovak Republic (2004) and Romania and Bulgaria (2007). It is in particular from some of these countries (Hungary, the Czech Republic, the Slovak Republic and Bulgaria) that many Roma people have migrated-and increasingly continue to do so-towards Western Europe, mainly into cities. This increasing migration gives rise to much political de- bate $^{1}$, as Roma are considered to have a very particular way of living which it is feared will infringe on social stability. Additionally, they are related to numerous social problems that have emerged or grown since their arrival in Western Europe by policy makers or in the media, such as (particular forms of) criminal behaviour, extreme poor housing conditions, noise and litter inconveniences, begging, etc. Consequently, a lot of action is taken at various policy levels, not least at the Eu-

\footnotetext{
1 See, for example, the Roma evictions by French president Sarkozy in 2010 and all forthcoming discussions (cf. Nacu, 2012a; Tran, 2010; Traynor, 2010).
} 
ropean level. In this complex situation, a recurring question of decisive importance is to what extent the migrations of Roma are different from other ones. Targeted measures are often legitimised by the particularity of Roma. In doing so, reference is made to an ongoing history of diaspora, exclusion, discrimination and even persecution (Fraser, 1995, 2000; Hancock, 1997); to specificities of the Roma culture (Fraser, 1995; Hancock, 1992; Liégois, 2007); or to the absence of a homeland of the Roma people, often in relation to a problematic social position in their countries of origin (e.g. Bancroft, 2005; Ringold, Orentstein, \& Wilkens, 2005). The field of tension between a need to confront social problems related with Roma on the one hand and the willingness to recognise Roma identity on the other hand, is very present here. It is in this tension the research at hand can be situated.

In this article, the question to what extent experiences and self-perceptions of Roma immigrants in Western Europe correspond with the way they are represented in contemporary policy discourses, will be further explored. As such, we build upon the significant contribution of Nacu (2012b), which stressed the centrality of the way in which identity has an impact on the politics of migration at European, national and local scales. The "ethnicisation" of Roma identity in policy measures influences the way these people contribute to the construction of this identity themselves. Throughout their contacts with public institutions, Roma are subject to struggles of definition and framing in which they use everyday strategies to try to turn the situation to their advantage. The pragmatic "use" of identity as constructed in policy may deliver benefits on the short term (e.g. by receiving support from target group oriented measures towards Roma). On the long term, however, there is a risk that this "use" will reinforce stigmatisation schemes. This process, of course, is not unidirectional. Beyond the question how a constructed identity shapes the politics of Roma migration, it may be questioned how self-definitions of Roma may in turn be meaningful to conceive of policy differently. What is at stake, then, are Roma's own attributions of meaning behind outer behaviour. The insight that the way the "Roma problem" is framed and reproduced in society is the most important obstacle hindering Roma political development (Vermeersch, 2002), compels us to take such an insider perspective seriously. Doing so, Roma's own definitions of their identity (and culture) may serve as a step-up to changes in the present socially constructed meaning-granting framework. Still, this commitment is not an easy task. In relation to the search for a proper understanding of the insider perspective, Bridges (2009, p. 120) refers to the need for an "ethical sensitivity" which outsiders need to bring to an enquiry into the experience of the other, i.e. the insider. Amongst other things, he mentions "the need for respect for and sympathy with oth- ers' desire to construct their own understanding of their lives and practice; caution about importing external frameworks of understanding which might be oppressive rather than emancipatory; and sensitivity in negotiating alternative and especially threatening understandings". Elsewhere, he takes the argument for taking an insider perspective into account a step further, recognising that "respect, care and dialogic relations are not enough. Research must be conducted in such a way that it contributes actively to the creation of a more just society" (Bridges, 2001, p. 383). He proceeds by saying that "the claim 'nothing about us without us' ought to be an ethical as well as an epistemological truism in educational research as a statement about the kind of relationship which should obtain between researcher and participant" (Bridges, 2001, p. 384). Insider understanding is not only about whose voices are listened to, but also about who is entitled to research them and how this can be done.

The starting point of our quest was an interest in what the people at whom initiatives are targeted have to say about the discussions they are subject to. Plenty is written on adequate policy strategies, but Roma themselves are only scarcely heard in the debate. An important presupposition of this position is that at this point the definition of "Roma identity" is to a certain extent open in the sense that it can be reframed or reconstructed differently. Our research focuses on how ethnic Roma who have recently migrated from Eastern Europe (in casu the Czech Republic and the Slovak Republic) towards Western Europe (in casu Ghent), define Roma identity themselves. Two research questions were central to our project: 1 . How do recently immigrated ethnic Roma in Ghent define their own identity and how/in what sense do they relate to "being Roma"; and 2. How does this self-identification correspond with currently predominant policy discourses towards Roma?

In what follows, we first provide some information concerning the research context. The situation of Roma in Belgium and the city of Ghent in particular will be described shortly, as well as local policy initiatives. We then proceed to the empirical part of our research, which consists of an in-depth case study with a limited amount of in-depth interviews. Based on our findings, we will argue that an insider perspective has an important added value not only for developing policy towards these people, but also for questioning these policy measures.

\section{Methodology}

\subsection{The Research Context: The City of Ghent, Belgium}

\subsubsection{Roma in Belgium: A State of Affairs}

It is estimated that there are about 30,000 Roma in 
Belgium (Council of Europe, 2012) ${ }^{2}$, although it must be stressed that there are no official numbers, as ethnic background is not recorded in the Belgian public administration system. Further research, moreover, shows that this number is going around since over five years and was taken over from older figures whilst most migrations are said to have taken place during the last few years (mainly since the expansion of the European Union as mentioned earlier) ${ }^{3}$. The Flemish expertise centre on migration and integration (since 2011, "Kruispunt Migratie-Integratie"; previously, "Vlaams Minderhendencentrum") provides a figure of 15,000 to 20,000 for Flanders and Brussels (Vlaams Minderhedencentrum, 2010), which fits quite well with the earlier, but as they mention themselves this number also goes back to 2003 (Kruispunt MigratieIntegratie, 2012). Still, there is a lack of more nuanced and relevant information.

Roma $^{4}$ in Belgium live in well-defined geographical spaces, mainly in the major cities (Brussels, Antwerp and Ghent are said to count for 90 per cent of the present Roma) but a few communities live in smaller municipalities too (e.g. Sint-Niklaas and Diest). Roma populations in these various cities can rather clearly be distinguished based on their countries of origin. While in Antwerp (as in Sint-Niklaas and Diest) most Roma come from former Yugoslavian states (mainly Kosovo, Macedonia and to a smaller extent Serbia and Montenegro), in Brussels it are mainly Rumanians. Ghent, in its turn, has a large population of Bulgarian and Slovakian Roma. Apart from these identifiable cultural and religious differences, the legal status between various groups may differ too. People stemming from other countries within the European Union can travel to Belgium freely, and settle under particular conditions $\mathrm{s}^{5}$. This is not the case for people who come from Kosovo or Macedonia, for example, as a result of which these people often reside illegally in the country. These dif-

\footnotetext{
2 i.e. 0.28 per cent of the total population which officially counts 10,4 million people.

${ }^{3}$ Cf. figures provided in Liégois (2007). Still, the European Commission (2011) presents this number as a 14 September, 2010 update. For a large discussion on problems related to similar estimations, see Hemelsoet (2010).

4 "Roma" should here be distinguished from the far smaller groups of Roms and Manuches (estimate ca. 300 people) or socalled "Woonwagenbewoners" [caravan dwellers] (estimate ca. 2000 people) who have the Belgian nationality and reside in the country since many generations (Vlaams Minderhedencentrum, 2010). Roma here refers to more recent immigrants stemming from Central and Eastern European countries of origin.

${ }^{5}$ Within the context of this article, we will not go deeper into the very complex legal conditions that are decisive whether one can settle in the country or not; but the major condition is "financial independence", which in practice almost always implies that at least one person of the family has a job.
}

ferences evidently have consequences for the particular living circumstances of various groups (Decoodt \& De Reu, 2009; Vlaams Minderhedencentrum, 2010).

\subsubsection{The Interesting Case of Ghent}

The city of Ghent seems an interesting case to further investigate for various reasons. First, the inflow of Roma is (albeit not in absolute numbers) probably nowhere as visible as it is in Ghent ${ }^{6}$. Second, this inflow consists of largely differing groups (cf. infra), which gives rise to a very particular situation in relation to group identification. Finally, a lot of initiatives towards Roma people are taken in Ghent, both by policy makers and NGOs. The foregoing properties explain why many discussions in the wider public debates in Flanders find their starting point in this city. The Roma living in Ghent can rather clearly be divided into three groups originating from various countries: Bulgaria, the Czech Republic and the Slovak Republic, and Rumania. Although some similarities can be observed, their motives of migration as well as their living circumstances, habits, integration patterns and survival strategies are to a certain extent different ${ }^{7}$. It is moreover remarkable that there is hardly-if not, any-communication between these three groups. Bulgarians generally seek alliance with the large Turkish (non-Roma) community in the city. It mainly concerns Turkish-speaking Bulgarians who are employed and housed by Turkish immigrants. Although their working and living conditions are in many cases abominable, they appeal only to a limited extent to social services. Slovaks struggle more difficulties in finding a job and are proportionally more de-

\footnotetext{
6 The number of legally residing Roma immigrants in Ghent was estimated to be 4,820 on a total population of 247,262 (i.e., 2 per cent of the population) on 31 December 2011. This estimation is based on official registrations of Central and Eastern European immigrants in population registers. The total amount of registered immigrants from these countries (EU10: Bulgaria, Czech Republic, Estonia, Hungary, Latvia, Lithuania, Poland, Rumania, Slovakia and Slovenia) was 9,433 at this moment, which is about four times higher than five years before. In absence of ethnic data, it is estimated by the cities integration service that 50 per cent of all Bulgarians and 90 per cent of all Slovaks and Czechs are ethnic Roma. This leads to total numbers of 2,815 Bulgarian, 1,737 Slovak and 268 Czech Roma. Rumanians are not included in the estimations, probably because there numbers are very limited. At the date of measurement, 175 Rumanians were registered in the city. It must be stressed though, that there are no clear criteria for the suggested percentages, and discussions with fieldworkers on their correctness persist. Moreover, unregistered immigrants are not included in these numbers and estimations for obvious reasons, which makes numbers even more uncertain.

7 Tremlett (2009) stresses large differences amongst various Roma communities. This heterogeneous character of the Roma implies large difficulties for universal policymaking for (all) Roma and moreover problematises homogenising discourses.
} 
pendent upon the social security system. Not rarely, their families count up to 10 or even 12 children with whom they often live in miserable circumstances in squats. Rumanians live in a smaller, rather close-knit community. Traveling back and forth between the place of origin (the city of Oraviţa and its surroundings), Ghent and other European cities is a common practice amongst this group. Their major source of income is begging in the streets. Most of the money they collect is sent to their home country in order to financially support their families and children who mostly stay there. Their ambitions to build up a life in Belgium are limited, as is their willingness to integrate into civil society (Hemelsoet, 2013). The hereby described situation explicitly illustrates the relevance of the question how policy makers can handle the present differences.

Before clarifying our empirical research, it might be interesting to have a look at local policy initiatives. The city of Ghent developed a particular policy to deal with the recent influx of Roma immigrants. In this policy, reference is made to the pressure that those new migrations exert on the social climate and on the supporting power of the local community. As the possibilities for local authorities to influence push factors (those are the factors which give people a reason to leave their countries of origin) are limited, the focus is mainly on so-called pull factors (factors of attraction for new immigrants to choose for Ghent more in particular).

As Philippeth and Philips (2010) phrase it in the city's policy document, "The city sets out a two-track policy by offering support through integration and settlement measures on the one hand, and taking repressive actions against all forms of (semi-)illegal practices on the other hand". Priority measures are situated on the following four levels:

1. Coordination and intensification of the policy towards intra-European migration. This should happen both horizontally (crossing different policy domains) and vertically (warranting the connection between different policy levels). A "Permanent Consultative Body", which will be responsible for further coordination, should be established.

2. Housing policy. This comprises proactive avoidance and consequent termination of squatting as well as further supervision of precarious living circumstances.

3. Residence, training and work. The establishment of a central information point for social workers and intermediates, the introduction of "bridging figures" and mediators and a more strict approach to irregular labour circuits are prior measures in relation to this topic.

4. Supra-local action. Amongst other things, this involves pointing out lacunas in legislation; sensibilisation for and provision of information on voluntary return to countries of origin; exert of pressure on European authorities; organisation of specific information campaigns towards particular cities and regions of origin.

By now, action has been taken on each of these four levels and this policy document has been brought into practice in its various dimensions. As the proposed actions suggest, the Ghent policy is highly oriented to integrate Roma into the existing system ("mainstreaming") and draws little attention to the potential role of local Roma communities in the construction of policies. When developing the policy described above, no Roma were involved.

\subsection{Framework}

The empirical research consisted of qualitative interviews conducted in the city of Ghent, Belgium between April and September 2012 with a total of 17 persons all self-identifying as "Roma" and originating from the Czech Republic and the Slovak Republic. The aim of the interviews was to retrieve in-depth insights rather than generalizability based on representativeness, which explains the rather limited number of respondents. Respondents were contacted by the spread of words in our own and the translators" networks, which largely explains the Czech and Slovak origin of all respondents. Interviews were based on a semi-structured questionnaire in order to fully establish the narrative aspect of the requested information. During the interviews, socio-economic profile, identity, and cultural habits were inquired. As mentioned by Silverman (2007), regarding the way of measuring identity and cultural aspects, it is best not to ask about these themes specifically, but rather to consider the whole encounter as an expression of identity and culture. As such, we tried to "deethnicise" the interview as much as possible. Specific questions about culture and identifications were introduced in the end, and cultural expressions during the interview were taken into account (see Table 1).

To overcome the language differences, two translators were contacted, proficient in either Slovak or Czech, and Dutch. Even though the researcher had personal connections with Roma people through more than six years of voluntary work with Roma people, one of the most difficult aspects was to find people who were willing to participate in our research. The main reason for non-participation was that few people were willing to identify as Roma. As we could experience ourselves in our search for respondents, "the long-standing experience of xenophobia and marginalisation faced by Roma over decades [in countries of origin] has inevitably led to a deep mistrust of the majority community" (UNICEF, 2011, p. 74). At the beginning of each interview, we carefully presented ourselves as "neutral" researchers, affiliated with Ghent 
University, and not in any way associated with the city administration (which we expected would only further nourish distrust). Furthermore we guaranteed the interviews to be anonymous, and only to use the obtained information in the context of our research. All 17 interviews were conducted at the respondents" residences.

\section{Results}

\subsection{Socio-Economic Profile}

All respondents had an official residence (in Ghent) except for one respondent, who was residing with her family in a squat. All respondents had access to (hot) water, toilets, bath room with shower, cooking facilities and heating. ${ }^{8}$ Only the family in the squat had no access to hot water and only had access to heating through a bad functioning electric heating machine. The latter family was also the only one mentioning that they did not have a sufficient income to buy enough food and clothes. One respondent was living on her own, one family had their children residing elsewhere,

8 It must be stressed that this situation is very probably not representative for many Roma living in Ghent. Neither was representativeness strived for when searching for respondents, as our main focus was on respondents who reside in Ghent since a relatively long period and aspire to stay here and to "form part" of Belgian society to a more or lesser extent. and in two cases the family was sharing the house with multiple families. The houses were often small and in very bad condition. Nine people mentioned that their house was too small for them.

Three respondents, of which a 19-year old youngster and two older people, had an income at the moment of the interview. One person was working part-time as a social assistant, and was the only respondent with a university degree, and also the most proficient in Dutch. Another respondent was working as a longshoreman, and got this job through a relative who was working at the same company. The third respondent with a job was working as a cleaning lady, and likewise found this job through a relative who was employed at the same place. These three respondents, together with three unemployed respondents, were also the only ones who were proficient in Dutch. Many respondents had been in Belgium for several years, but had never worked. Without any exception, however, every respondent commented that they would really like to work, and that they were looking for employment. It was often mentioned that they had not find a job yet because of their poor knowledge of Dutch. In addition, most of the women wanted to focus on managing the household and the children. One person was already residing in Belgium for over 18 years, was very proficient in Dutch, but had never found a job, despite her own intents.

Table 1. General characteristics of respondents (age; gender; nationality; time of residence in Belgium; number of children; source of income).

\begin{tabular}{lllllll}
\hline$N^{\circ}$ & Age & Gender & Nationality & Years in Belgium & Children & Income \\
\hline 1 & 40 & F & Slovak & 6 & 4 & Welfare: unemployment, children \\
2 & 45 & M & Slovak & 4 & 4 & Welfare: unemployment, children \\
3 & 30 & M & Slovak & 5,5 & 1 & Income, welfare \\
4 & 41 & F & Slovak & 2 & 4 & Welfare: unemployment, children \\
5 & 45 & M & Slovak & 1,5 & 4 & OCMW , children \\
6 & 42 & F & Slovak & 0,2 & 4 & Donations \\
7 & 19 & F & Slovak & 2 & Pregnant & Income \\
8 & 16 & M & Slovak & 6 & 0 & Student \\
9 & 37 & M & Czech & 2 & 3 & Welfare: unemployment, children, donations \\
10 & 40 & F & Czech & 2,5 & 3 & Welfare: unemployment, children \\
11 & 33 & F & Czech & 18 & 2 & Welfare: unemployment, children \\
12 & 27 & M & Czech & 12 & 1 & Welfare: unemployment, children \\
13 & 35 & M & Czech & 5 & 4 & Welfare: unemployment, children \\
14 & 30 & M & Czech & 4 & 2 & Income \\
15 & 33 & M & Czech & 8 & 3 & Welfare: unemployment, children \\
16 & 37 & M & Czech & 9 & 3 & Welfare: unemployment, children \\
17 & 18 & M & Czech & 10 & 0 & Student \\
\hline
\end{tabular}

${ }_{9}^{9}$ Public Social Welfare Center (Openbaar Centrum voor Maatschappelijk Welzijn). 


\subsection{Access to Services (Healthcare, City Services, Education)}

None of the respondents felt discriminated by any of the city services, healthcare institutes or educational institutions. Except for one respondent, all subjects and their families had access to affordable healthcare. Most families found their doctor or medical centre through referrals of their connections. All subjects were satisfied with their experiences with their medical centre. ${ }^{10}$ We also specifically asked about the experiences of the people with city services (employment aid, police, integration office,...). Almost all respondents had positive experiences with these services. Interestingly, when asked if they "trusted" that these instances handled in their best interests, the answers were negative. Although they mentioned they can easily access city services, a basic distrust and discontent towards these services remains. It was often mentioned that the information was not specifically targeting "Roma"issues, and lacked sensitivity to these issues. These issues concerned the receipt of information about their rights and opportunities (employment, etc.) in Belgium. Still, they seemed to uptake a rather powerless and expecting position, and limited the interaction with the service providers themselves. As depicted by two respondents:

I: How about the $\mathrm{OCMW}^{11}$ ? Are you confident that these people really try to help you?

R: Sometimes yes, sometimes not. I do not really know what my rights are. I do know about all the things I need to do, but I do not know about my rights when I visit an OCMW.

I: And did you ask about your rights to the OCMW-employees?

R: I asked once, and then I got a response that I did not really understand, it is all so difficult.

I: Are you saying that communication about your rights should be improved?

R: Yes, totally. People should better explain what our rights are, and maybe give some more specific information for Roma. (Czech man, >2 years in Belgium)

\footnotetext{
10 Throughout the first three months of their residence, intraEuropean immigrants officially reside in the country under "tourist" status. If they are willing to stay longer, they are expected to register in the city and continue to be self-supporting after that period (which generally implies to find a job). If they do not succeed to do so, they become irregular migrants. Concerning medical care, this implies that within the first three months they can make use of medical services as other tourists can. For irregular migrants, "urgent medical care" is provided; this includes free care in case of "urgent" need, a concept which in practice appears to be stretchable depending on the particular doctor/aid supplier.

11 Cf. footnote 8 .
}

I: What is your position regarding the city services? Do you trust them?

$\mathrm{R}$ : In general I think it is very positive that the city welcomes diversity. The quality of some services is low however. (...) Some services say that they provide certain services, but there is often something wrong. Often they do not know the background of the people, the social status, the family situation. They should also be better prepared to work with certain cultures and people, as Roma. (Slovak man, $>4$ years in Belgium)

Regarding their trust in the police, the answers were similar. The respondents declared that they felt they could make use of the police, and never had any bad experiences with them. When asked if they would also really contact the police in very difficult situations (e.g. difficult neighbourhood situations, fights,...), the respondents gave a similar answer: they would not contact the police, unless it would get "really bad".

\subsection{Migration}

The causes of migration to Belgium are diverse. Two respondents refused to talk about this topic, thirteen others declared that the major push factors of migration were economic issues.

I: Why did you leave your home country?

$\mathrm{R}$ : There was nothing there. (...) If you work there, you would earn 5 euros per day. So you go to work, and they do not even pay you. That way you can never earn enough money to buy a house. Everything is expensive there. And when you have children: milk, food, nappies,....It is all very expensive. Roma are also being discriminated. There are many advantages of living here.

Discrimination of Roma in their home country was mentioned by nearly all respondents and for some of them this was in particular the reason they moved to Ghent. As described by a respondent:

I: Why did you leave your home country?

R: But with people like us, us Roma, we are like dust under the feet of other people. And that is not good. When they see us, they say: "Oh, a gipsy, they don't want to work, etc.... but that is not true. A lot of people already showed this is not true. We want to work, we want to live like other people. Oh yes (sighs) for instance, if children lack certain things in those countries, they can get those opportunities here. For instance in our country our children don't have the opportunity to go to school when they get older, but 
here, yes they even get something like money, for instance one hundred euro, or how much....There it is not the case, there they can go to school till they are eighteen years old, and then it is finished. Or for instance for being a doctor, there it is seven years and then it is finished, here you can still continue and study to be a specialist. But this is the way you can become a doctor, if you go to school for many years, then you can learn to do anything.

The particularly violent nature of discrimination against Roma in their home countries was mentioned a number of times. One of the respondents stated that his migration was informed by the fact that he had been threatened to death for being Roma.

I: Why did you leave your home country?

R: Well, I was nineteen years old, living with my parents. The skinheads came to our restaurant already three times. Well they came, and after the third time my father said "No, we have to leave everything" and we decided to come here. Twice the skinheads wrecked everything in the restaurant. And one of the skinheads...he stabbed a knife into my mother's chest...not such a big knife...the wound was not that big. But the bass.... think it was the boss of the skinheads raised his gun towards the sealing...not us...the sealing. And he said "If you dont leave"...to my father "if you don't leave with your family, I will come again, and you will have even more problems...and that happened. And the third time, they broke everything in the restaurant...my mother had problems with her chest...I was so scared...I was nineteen and the skinheads were looking at me and my mothers, the grabbed me and dragged my upstairs, we lived...that's why. At that moment the police still came, my father called them....After that we maybe still stayed for two or three days and we left...

When asked why specifically they decided to come to Belgium (pull factors), all respondents answered that they had family or friends here. Most respondents reported they were relatively happy in Belgium, and all respondents were keen on staying here.

\subsection{Social Organisation}

We asked our respondents about existing Roma organisations in Ghent, and were interested if they would be interested in getting more connected. All subjects responded that there were no official channels or groups by which the Roma people are in contact with each other. Six of the Slovak respondents had heard about Opré Roma, an organisation set up by a Slovak Roma, taking initiatives specifically targeted at Roma. Besides this project, little was known about any project specifically working with Roma. Interestingly, during our study, Opré Roma took the initiative to start a footballteam, which was a tremendous success. On the first training 30 youngsters were present, and this amount kept growing each training. This might also be related to the fact that the communication among Romayoungsters might go faster than the communication between adults, but it did demonstrate a clear interest of at least some Roma people to get more engaged in "organised" activities.

Interestingly, when asked if they would be interested in the mere organisation of the Roma as a group, almost all respondents answered they did not feel the need to organise themselves. The social network of most subjects consisted of their (far) family, and there was little interest to get connected with other Roma (groups) in a formal way.

\subsection{Self-Identification}

We asked respondents to which extent they affiliated themselves with Belgians, non-Roma and Roma from the country of origin, Belgium and other countries, and how they felt about the "other" Roma groups.

The affiliation with the country of origin was rather limited. Most respondents had little or no contact with people in their country of origin, other than their direct family. Furthermore, the social network of our respondents in Ghent consisted almost entirely of direct family members, and Roma from the same group and region of origin (who often appeared to be "far" family).

With regard to "identification", our interviews revealed some differences between (older) adults and youngsters. Children identified even less with their country of origin, as demonstrated by their very limited interests in these countries, and had a stronger focus on improving their life and social network in Belgium. Their social network was significantly "broader" than the networks of the adult respondents. All the youngsters in our interviews had Flemish friends, as well as friends from a different origin, as a result of the social contacts within their schools. In addition, they were able to speak Dutch reasonably well.

Distinctions between the different Roma groups were established here as well. As mentioned, the social network from the (adult) respondents consisted almost entirely of Roma from the same region of origin, and simultaneous migrations. Additionally, most respondents had many prejudices about the "other" Roma. As discussed by some respondents:

$\mathrm{R}$ : The things we share as Roma are the language, the music, food, dancing, and that is all. Our parents have always been poor. They had no means and time to spend too much time on the educa- 
tion of their kids, it just did not happen.

I: Does that make it hard to speak in general terms about Roma?

$\mathrm{R}$ : Yes. There is also a lot of rivalry between Roma. They [the Slovak Roma] say that we are not real Roma because we do not wear that type of clothes, and dye our hair blonde. There are also many differences between the country side and the cities. I have no contact with other Roma in Ghent, only with my Roma neighbours, and my Roma family.... With Belgians I have no contact at all, except for $* * *$ who sometimes comes here to help.

R: They sometimes confuse us with caravan dwellers! But we are not! They drive around in their cars and steal....But we don't!

I: Can you tell me about the people in your social network in Ghent?

R: I mostly deal with my family, yes, my family is the most important to me. With Belgian people I rarely make contact, unless for specific services. I do know some Slovak Roma who live next to me however.

I: Can you tell me about the interaction between the different Roma groups here in Ghent?

$\mathrm{R}$ : There is very little interaction, because this is not supported by the government, or by the offered services. They do not support the Roma culture. We have very little contact because at first sight, you do not know who is Roma, and who is not. You cannot talk to the people on the street, so you do not know about the other Roma.

These testimonies suggest that the main reason why various Roma (groups) do not know each other is not a certain "distance", but rather the fact that they are not familiar with each other's existence. It is particularly the (extended) family who plays a major role in the daily life of the Roma.

When asked with which ethnicity ("Belgian", "Flemish", "Roma", "Slovak",...) they identify most, all adult respondents said that they affiliated most with Roma, followed by "Slovak" or "Czech". The youngsters, however, responded differently to this question. They all affiliated most with "Roma", but after that they strongly preferred the "Belgian" identity. In addition, they minimised their Roma-identity. As mentioned by some respondents:

I: Who do you most identify with? Roma, Belgians, Slovaks,...?

R: With Roma. But not at school. There it does not matter that much either, and there I play a lot with my other [non-Roma] friends. I:

Do you see yourself as Slovak?

R: No, not really. I do not know, I have very little affiliation with Slovakia, and I do not want to go back.

I: And do you look at yourself as a Belgian?

R: Just a little, but not really....I do not know. It does not really matter to me either. Nobody ever asks it to me, and we are all equal. You, me, we are all people.

I: You will soon go back to Slovakia for a holiday, are you looking forward to it?

R: Not really no. I have not been there in years, it has been too long ago.

I: And are you not excited to go back?

R: No, not really. Slovakia is not my country anymore, I do not feel it that way. I am also not proficient anymore in the language. And I like being here....And I have a cat here, I need to care for it. Do you want to take care of my cat while I am gone?

We were also interested in hearing to what extent people explicitly declare their (Roma) identity in social or professional environments. Most respondents told us that they usually do not mention they are Roma, but rather mention their country of origin. The reason for this is that services in Belgium do not require people to mention their ethnic background, but only their nationality.

\subsection{Culture}

Culture was discussed both directly and indirectly. We explicitly asked about the importance of language, religion, and the perspective on relationships. In addition, we inquired themes that would spontaneously arise during the interview such as hygiene, music, mobility,..... Indirectly, we were confronted with culture, in the sense that it manifested itself continuously during the interview, from the moment we entered a living room onwards, until the moment we left.

The tendency to think on the short term that is frequently related to Roma, was often reflected in the interviews. It manifested itself most obviously in the way interviews were planned. Without exception, they had to be planned maximum two days in advance, because the availability of the people was too difficult to estimate otherwise. It was also manifested by the academic choices made by the youngsters, who were all very keen to start working as soon as possible.

We asked to which extent they were speaking Rromani ${ }^{12}$ with each other, and if they were passing it to their children. Twelve respondents indicated that

\footnotetext{
12 Rromani or Romanes is the "proper" language of the Roma. This language exists in numerous varieties and even more dialects, which differ a lot between each other. Moreover, it has no standardised written form. For further reading, see Bakker et al. (2000) and Matras (2005).
} 
they mainly speak the language of their country of origin (Romanian, Slovak, Czech) with their children. Two of the three interviewed youngsters understand Romani, but do not really use it.

The importance attributed to cleanliness and personal hygiene was a recurrent theme in the interviews. We mention it, because it reappeared often, and in a similar way with most respondents. For example, respondents stressed the importance of taking off shoes before entering a classroom or a house, which is a rather uncommon habit for Belgians. Additionally, the topics referred to by the respondents in terms of "hygiene" often raised spontaneously during a discussion in rather surprising ways.

I: Would you like your child to marry another Roma? Or does that not matter?

R: With a Roma, a Belgian, anybody... it does not matter to me. If only it is a good husband. But I would prefer her not to marry a Turkish person. I: Why?

R: They are not very hygienic...They are circumcised, it is not clean...

\section{What an Insider Perspective May Add to Policy Construction}

Though our research was very explorative, some of our preliminary results are surprising. First, our findings reveal that there is a large gap between Roma and the provided services. Even though the respondents did not experience direct forms of discrimination, there is a general and explicit distrust in these services. A possible reason for this distrust may be found in migration histories. Most respondents identify economic issues as the major pull factor of migration, which corresponds with earlier research of Cherkezova and Tomova (2013) who identify "the production and employment restructuring, the access to job opportunities, and the level of welfare" (p. 153) as three major factors that result in similar migratory behaviour. Nonetheless, reference is almost systematically made to profound discrimination and racism in their countries of origin. Van Baar (2011) describes recent measures taken in Eastern European Countries that set forward an activation and reintegration of Roma. Recently implemented neoliberal activation programs and welfare reforms on the contrary lead to increasing treatment of Roma as an underclass in an exploitative and dehumanizing manner. These findings can be complemented with how respondents describe their feeling of being treated in a demeaning manner and given less economic or educational opportunities in their countries of origin. Also, while Roma often share economic and security motivations for migration, insecurity because of community tensions and violence are identified as particular for Roma (CDMG, 1995). These hostilities and sometimes even the collective awareness of these hostilities often trigger Roma migration (Matras, 2000). Our findings concur with this statement illustrating how severe violence and threats linked to discrimination are prevalent and motivate migration. While nearly all respondents describe no negative experiences with institutions or services, a general distrust and an expectation of discrimination in services is mentioned. Discrimination is thus a priori presumptions of Roma in their contacts with services. This could be linked to the fact that Roma anticipate discrimination everywhere (Cherkezova \& Tomova, 2013). Roma often describe exclusion from essential services, hostilities and violence by state institutions in their host country (Amnesty International, 2014). Moreover, studies reveal how Roma are in reality confronted with discrimination and racism when trying to access services like labour market, health, housing and education (Craig, 2011). Regardless of the lack of incidences of discrimination with services the feeling of distrust is an important finding to take into account within policy making towards these groups. Since although integration and participation of Roma is "expected", the provision of a proper political framework where trust issues between Roma and the oftendistrusted governmental institutions are addressed is lacking (Van Baar, 2014).

Second, most respondents primarily identify with being "Roma". Surprisingly though, further questions on this topic revealed that this identification had few connection with the broader meaning which is generally attributed to it, i.e. Roma as an ethnic group living in diaspora all over Europe (and to a lesser extent in other continents). For the respondents, "Roma" rather refers to the informal social networks these people are living in. Those networks are mainly comprised of large extended families in which everybody is somehow related to each other, either through blood lines and/or marriages and if not as close neighbours (Nacu, 2012b). "We, the Roma" as distinguished from the rest of society refers to this extended family rather than to Roma as an ethnic group. This finding strongly corresponds to earlier findings that show how Roma often first and foremost present and identify themselves with their extended family (Liégeois, 2007). Moreover, respondents often expressed prejudices about other Roma (groups), which in some cases results in an unwillingness to identify themselves with these other Roma (groups). This became clear in the answers to questions on the desirability of forms of social organisation: there certainly is a kind of interest in social organisation but not merely for Roma as a(n ethnic) group. Implicitly, this is further affirmed in the self-group Opre Roma, which is received very enthusiastically but solely consists of Slovak Roma from the same area of origin.

Third, our findings revealed important intergenerational differences. Whilst for adults most contacts are 
limited to in-group communication within the extended family, the youngsters in our interviews have broader social networks and a lot more out-group contacts. Moreover, they far less identify with countries of origin and rather feel Belgian than e.g. Slovak or Czech. These findings comply with studies carried out with young non-Roma-migrants that describe intergenerational differences in acculturation with young migrants getting more involved in the new culture than their parents (Birman \& Poff, 2011). Our study showed that although these young respondents still feel Roma in the first place, this identification is clearly less strong. Apart from that, they also have Belgian and other nonRoma friends and they generally have better Dutch language skills than their parents. This is probably due to education: throughout schooling, they structurally and repeatedly get into contact with other children, which is evaluated positively by the youngsters themselves. The need for an affirmation of a Roma identity as being different from, opposed to or "outside" mainstream society seems thus to be less present in youngsters than in (older) adults.

Apart from the former findings some "family resemblances" amongst the respondents were found. First of all, the short-term perspective in their thinking and behaviour was very present. They referred to how planning was problematic to them and in almost every sense they expressed a day-to-day living style. Concerning language, there was only a partial use of Romani. Most respondents speak the official languages of the countries of origin at home, in some cases mixed up with Romani. Third, hygiene was a recurrent theme in the interviews. The opposition between "clean" and "dirty" structured a lot of observed behaviour and was often explicitly introduced in conversations. This relates to the importance attributed by Roma to cleanliness as well as ritual purity referred to in various studies as an important factor to take into account when conceptualizing service delivery that can enhance compliance and satisfaction of Roma people. For example, Vivian and Dundes (2004) refer to culturally distinct beliefs and behaviours of Roma related to health, knowledge of which is important to take into account in the provision of services such as health care. Although other research confirms some of our findings, we consciously make use of the term "family resemblances" amongst respondents rather than "cultural characteristics". Not only is our sample of respondents too small to generalise our conclusions, it would also run the danger of referring to a broader "Roma culture" which, as we have clarified above, has dangerous consequences. It is also unclear whether the described features refer to cultural characteristics or rather properties that relate to the particular-often deteriorated-living conditions of these people (it is for example plausible that the living circumstances argument counts for thinking on the short term).
This brings us to the added value of an insider perspective to policy making. Roma narratives supply interesting input for policy making for various reasons. First, we can distinguish informative-interpretative reasons. Roma narratives offer insights which could not be retrieved elsewise and as such they "inform" policy making: they may break through existing prejudices, affirm existing conceptions, clarify underlying motivations or causes and bring in new elements. As such, they add to the discussion on a proper understanding of social practices. The latter are not static realities though: social practices change over time and therefore the process of understanding is never-ending. That brings us to the second set of reasons, which are political-interpretative. Stories do not only inform us about a (static) reality, they in turn contribute to the constitution of that reality and form part of it in a creative way. This political dimension relates to one of the purposes of voice-giving: taking voices or perspectives into account is a democratic act. Interest in these narratives opens a space for participation in an on-going conversation and discussions on who Roma are and what is in their best interest. What they say (and thus who they are) is literally "taken into account": it forms part of the societal debate. Concerning identity, there are moreover good arguments to say that they are the most privileged actors to speak: who else is in a better position to say who they identify with and which group(s) they belong to?

There are thus good reasons to take an "insider perspective" into account beside the voices of other relevant stakeholders when constructing policy ${ }^{13}$. Still, the former arguments sound rather abstract. Some arguments as well as examples are presented of how Roma "bring in" something new or different. But what are the implications of this added "information" and how far do political implications reach? In the concluding paragraph we will further focus on the implications of the foregoing for the way policy towards Roma is currently conceived of.

\section{How an Insider Perspective May Question Policy}

This concluding paragraph stretches the developed argument a step further. It is our hypothesis that selfdefined identities developed within an insider perspective may not only add to policy but can also be useful to question the latter in a more profound way. As Ver-

\footnotetext{
${ }^{13}$ Evidently, what is eventually aimed for is a dialogue between all involved societal stakeholders. Although the scope of this article is somehow "limited" to the insider voice of a sample of Roma in Ghent, it is part of a broader study that also maps the perspectives of policy makers, professionals, and volunteer workers (see Hemelsoet, in press). Only by involving each of these perspectives, a well-informed policy doing justice to all involved stakeholders can be acquired.
} 
meersch (2012, p. 1196) states, "the current EU appeals for increased attention entail the creation of a political space for the formation and contestation of new understandings of who the Roma are, what they need and how they should be helped (Simhandl, 2006, 2009). In other words, the EU has now joined a complex political game of framing and reframing the Roma". What then are the consequences of taking "insider voices" into account in this political space or game of contestation? By bringing in the question how Roma identify themselves, the present article invades the discussion on the desirability of targeted and mainstreaming initiatives.

To summarise again, our major conclusions stress the following: 1 . there is a strongly mentalised gap with (institutionalised) majority society, 2. people first and foremost identify with being "Roma", but attribute a far more limited meaning to this concept compared to how this concept is usually understood both in the public debate and in scientific research (i.e., as an ethnic group or an international political/cultural/... movement) and 3. there are intergenerational identification differences (youngsters having a lot more outgroup communication and identifying less strictly with being Roma than older adults). These conclusions stress the present distance between the specific community (i.e. the own network which predominantly consists of the extended family) and mainstream society, mainly for elderly people. There is no desire to identify with the broader Roma community; as far as this is the case, it involves a local community of familiar people. This insider perspective expresses no support whatsoever for a targeted approach towards "the Roma" as such. Moreover, the affirmation of a present gap with the rest of society further strengthens the argument against particularisation. Listening to the insider narratives of Roma might imply recognising them as persons, rather than as Roma. As a Roma youngster framed it strikingly in one of the above quotations: "It does not really matter to me... we are all equal. You, me, we are all people." That conclusion may of course be transferred to other minority groups too. Its particular importance for the Roma lies in current policy discourse towards this group. The example of Ghent's policy is representative for a broader European tendency, although in its formulations it refers less explicitly to Roma and inclusion as guiding concepts. The major distinctive feature of this tendency is its directedness towards a particular (ethnic) target group which is moreover defined in terms of societal problems. Whether it concerns criminality, a condition of poverty, racism or discrimination seems to be of secondary importance; that these are presented as features of a culture is what is at stake here.

This observation may be surprising, as this approach towards integration of ethnic minorities has been left behind increasingly during the past few dec- ades. And although policy makers may find good reasons to stick to an ethnic minority target-group oriented approach in the incomparable differentness of Roma with regard to other groups, the insider perspective seems to bring about a somehow different story. Its implications for policy may be far-reaching:

- The plea for "a right to self-identification" of Roma does not only bring about new, adapted definitions of the Roma concept "from the inside"; it moreover questions whether policy should still be directed towards Roma as such (i.e., as a distinguished target group).

- Rather than reframing Roma in current policy making, the insider perspective reframes the meaning of inclusion. What matters most to Roma is not the content of the name of the ethnic group they belong to, but rather how they are treated: they prefer to be approached as "people" instead of "Roma". As such, a direction towards a different understanding of inclusion is suggested.

Of course, it would be a dangerous pitfall to generalise these conclusions as being the insider perspective of the Roma. Statements should not be generalised all too much. Not going deeper into much of the political debate on social participation possibilities, it must be stressed that a massive volume of studies on Roma has been produced already in Central and Eastern Europe. Increasingly, the voice of Roma themselves is heard in both scientific, policy and interest group research. In Western Europe though, such studies are still very scarce. Moreover, when Roma are taken into account both within scientific research and policy making, large discussions remain on representativeness. Within the Romani movement, the question who gets the mandate to speak on behalf of the Roma is recurring since over two decades. It is unclear how a legitimate Romani representation can be created, meanwhile a "Roma political elite" that is regarded as representative of the Roma, has come to existence. As intellectual activists, this elite risks losing its connection with "ordinary" Roma citizens as well as grassroots advocacy movements (Vermeersch, 2007, pp. 208-211).

Consequently, there are probably good reasons to state that the sample of this enquiry is not representative for all Roma in Ghent, and that Ghent is not representative for the situation of Roma all over Europe. Other Roma in Ghent or elsewhere obviously may have a different opinion about things. But as we mentioned in the beginning of this article, this kind of generalisation was not our aim. That does not restrict the impact of the respondents' perspective in any sense though. On the contrary, we hope that the presented insider perspective may fuel broad discussions in a fundamental way: because however few they are, what they say, it is our opinion certainly in this case, matters a lot. In 
what sense then does it matter, if it is not to be generalised nor can it claim representativeness? Smeyers (2009) refers to the limits of the predominant interpretation of insider understanding as experience-based. The latter evidently incurs insurmountable problems. Experience is highly liable to subjectivity between individuals: it always refers to a subject who is having this experience. This evidently follows from the insight that it is very improbable for two people to have the same experience for participating in it. As such, the "knowledge" produced by a small sample of respondents indeed is limited. Consequently, Smeyers introduces an alternative form of insider understanding. The question at stake here is in what sense taking part in $a$ practice is an issue of understanding. The one who is part of a practice evidently is someone "who knows how to go on" and does so in a particular way. The focus thus shifts from "knowledge" to "doing" and being entitled to do so in the future. What we can learn from insiders is "what makes sense" to them as insiders. Exactly this is what privileges insiders: they know why they go on as they do. They have chosen to take a particular route exactly because that route makes sense to them. As the above-mentioned implications for policy proved, what makes sense to them may indeed be helpful to "know how to go on": not to find "the" proper definition of who the Roma are through new knowledge, but to value an insider perspective's contribution "to go on" shaping the society we all live in. And in that story, we are all insiders.

\section{Acknowledgments}

The life of the second author of this article, Pauwel Van Pelt, was tragically taken in a traffic accident while writing this article. I hope that this final result does justice to his ideas as I tried to my best to further fulfil our shared interest and attempt to co-construct the space for an insider perspective in research as well as policy making on Roma during the past few years and months.

\section{Conflict of Interests}

The authors declare no conflict of interests.

\section{References}

Amnesty International. (2014). We ask for justice. Europe's failure to protect Roma from racist violence. London: Amnesty International.

Bakker, P., Hübschmannová, M., Kalinin, V., Kenrick, D., Kyuchukov, H., Matras, Y., \& Soravia, G. (2000). What is the Romani Language? Hatfield: University of Hertfordshire Press.

Bancroft, A. (2005). Roma and Gypsy-travellers in Europe: Modernity, race, space and exclusion. Research in Migration and Ethnic Relations Series.
Hants, UK/Burlington, US: Ashgate Publishing.

Birman, D., \& Poff, M. (2011). Intergenerational differences in acculturation. Encyclopedia on Early Childhood Development (pp. 1-8). Montreal: CEECD.

Bridges, D. (2009). Education and the possibility of outsider understanding. Ethics and Education, 4(2), 105-123.

Bridges, D. (2001). The ethics of outsider research. Journal of Philosophy of Education, 35(3), 371-386.

CDMG. (1995). The situation of Gypsies (Roma and Sinti) in Europe. Strasbourg: Council of Europe.

Cherkezova, S., \& Tomova, I. (2013). An option of last resort? Migration of Roma and non-Roma from CEE countries. Roma Inclusion Working Papers. Bratislava: UNDP.

Council of Europe. (2012). Estimates on Roma population in European countries. Brussels: Council of Europe.

Craig, G. (2011). The Roma: A study of national policies (European Commission Report). Brussels: European Commission.

Decoodt, F., \& De Reu, S. (Eds.). (2009). Kosovaarse Roma in het Waasland. 10 jaar beleid met Roma in Temse en Sint-Niklaas. Gent: ODiCe vzw.

European Commission. (2011). An EU framework for national Roma integration strategies up to 2020: COM/2011/0173. Brussels: European Commission.

Fraser, A. (1995). The gypsies. Oxford: Blackwell Publishers.

Fraser, A. (2000). The present and future of the gypsy past. Cambridge Review of International Affairs, 13(2), 15-31.

Hancock, I. (1992). The Eastern European roots of Romani nationalism. In D. Crowe, \& J. Kolsti (Eds.), The gypsies of Eastern Europe (pp. 133-150). Armonk, NY: M.E. Sharpe.

Hancock, I. (1997). The struggle for control of identity. Transitions, 4(4), 36-44.

Hemelsoet, E. (2010). To Frame the unframable: Quantifying irregular migrants' presence. In P. Smeyers \& M. Depaepe (Eds.), Educational research: The ethics and aesthetics of statistics (pp. 97-114). Dordrecht: Springer.

Hemelsoet, E. (2013). Roma in het Gentse onderwijs: een verhaal apart? Gent: Academia Press.

Hemelsoet, E. (in press). Whose problem is it anyway? Realising the right to education for Roma children in Ghent, Belgium. Romani Studies, 25(1).

Kruispunt Migratie-Integratie. (2012). Roma in Vlaanderen. Brussels: Kruispunt Migratie-Integratie.

Liégois, J.-P. (2007). Roma in Europe. Strasbourg: Council of Europe Publishing.

Matras, Y. (2000). Romani migrations in the postcommunist era: Their historical and political significance. Cambridge Review of International Affairs, 13(2), 32-50.

Matras, Y. (2005). The role of language in mystifying 
and de-mystifying Gypsy identity. In N. Saul \& S. Tebbut (Eds.), The role of the Romanies (pp. 53-78). Liverpool: University of Liverpool Press.

Nacu, A. (2012a). From silent marginality to spotlight scapegoating? A brief case study of France's policy towards de Roma. Journal of Ethnic and Migration Studies, 38(8), 1323-1328.

Nacu, A. (2012b). The politics of Roma migration: framing identity struggles among Romanian and Bulgarian Roma in the Paris region. Journal of Ethnic and Migration Studies, 37(1), 135-150.

Philippeth, K., \& Philips, F. (2010). Intra-Europese migratie en de Stad Gent. Impact, visie en beleid. Unpublished work.

Ringold, D., Orentstein, M. A., \& Wilkens, E. (2005). Roma in an expanding Europe: Breaking the poverty circle. Washington, DC: The World Bank.

Silverman, D. (2007). A very short, fairly interesting and reasonably cheap book about qualitative research. London: Sage Publications.

Simhandl, K. (2006). "Western gypsies and travellers" "Eastern Roma": The creation of political objects by institutions of the European Union. Nations and $\mathrm{Na}$ tionalism, 12(1), 97-115.

Simhandl, K. (2009). Beyond boundaries? Comparing the construction of the political categories "gypsies" and "Roma" before and after enlargement. In N. Sigona \& N. Trehan (Eds.), Romani politics in contemporary Europe: Poverty, ethnic mobilisation and the neoliberal order (pp. 72-93). Houndmills: Palgrave Macmillan.

Smeyers, P. (2009). Education, educational research, and the "grammar" of understanding: a response to David Bridges. Ethics and Education, 4(2), 125-129.
Tran, M. (2010, September 29). Roma expulsions: EU to start legal action against France. The Guardian.

Traynor, I. (2010, September 16). Nicolas Sarkozy rounds on critics and vows to keep dismantling Roma camps. The Guardian.

Tremlett, A. (2009). Bringing hybridity to heterogeneity in Romani Studies. Romani Studies, 19(2), 147-168.

UNICEF. (2011). The right of Roma children to education. Position paper. Geneva: UNICEF.

Van Baar, H. (2011). The European Roma: Minority representation. Memory and the limits of transnational governmentality. PhD Dissertation, University of Amsterdam, The Netherlands.

Van Baar, H. (2014). Participatie, veiligheid en beeldvorming van Roma minderheden: Een kritische reflectie op het Nederlandse beleid. Justitiële Verkenningen, 40(5), 86-98.

Vermeersch, P. (2002). Ethnic mobilisation and the political conditionality of European Union accession: The case of the Roma in Slovakia. Journal of Ethnic and Migration Studies, 28(1), 83-101.

Vermeersch, P. (2007). The Romani Movement. Minority politics and ethnic mobilization in contemporary Central Europe. New York/Oxford: Berghahn Books.

Vermeersch, P. (2012). Reframing the Roma: EU initiatives and the politics of reinterpretation. Journal of Ethnic and Migration Studies, 38(8), 1195-1212.

Vivian, C., \& Dundes, L. (2004). The crossroads of culture and health among the Roma (Gypsies). Journal of Nursing Scholarship, 36(1), 86-91.

Vlaams Minderhedencentrum. (2010). Werknota: Roma in Vlaanderen, knelpunten en aanbevelingen. Inspiratie voor het beleid. Unpublished work.

\section{About the Authors}

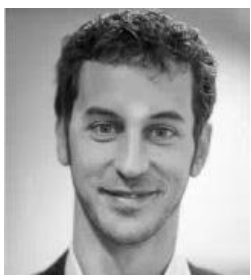

\section{Dr. Elias Hemelsoet}

Elias Hemelsoet conducted research at the Department of Educational Theory and the Department of Social Welfare Studies at Ghent University, Belgium. His primary areas of scholarship are politics of education, Roma people, irregular migration, and social policy. His PhD was titled "A Critical Appraisal of Policies and Practices Focusing upon the Right to Education: The Case of the Roma in Ghent" and he has published in various international journals.

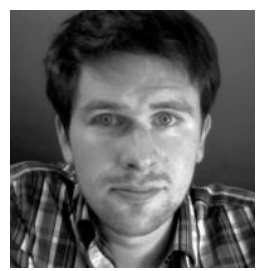

\section{Pauwel Van Pelt}

Pauwel Van Pelt + worked as a researcher at the Department of Experimental Clinical and Health Psychology of Ghent University. He also finished a master-after-master degree in Conflict and Development Studies, in which he conducted a research project on the identity and integration of Roma in Ghent, Belgium. 